\title{
BUDAYA GAGAS PERI SUKU OSING DI BANYUWANGI
}

\author{
Syamsu Hadi Bahtiar ${ }^{1}$, Dhalia Soetopo ${ }^{2}$ \\ Fakultas Keguruan dan Ilmu Pendidikan, Universitas PGRI Banyuwangi ${ }^{1}$ \\ Email: tiarhadi0@gmail.com \\ Email: dhalia.soetopo@gmail.com
}

\begin{abstract}
Kabupaten Banyuwangi merupakan kota di ujung timur pulau Jawa dengan luas wilayah $5.782,50 \mathrm{~km}^{2}$. Banyuwangi terbagi menjadi 24 kecamatan dan 217 desa/kelurahan.Kondisi geografis meliputi selat Bali yang merupakan batas dengan propinsi Bali di sisi timur, dataran rendah sebagai lahan pertainan dan ladang di wilayah bagian utara dan selatan, serta daerah dataran tinggi (gunung Ijen dan gunung Raung) di sisi barat sebagai lahan perkebunan.Selain itu, Banyuwangi merupakan pusat kerajaan berdasarkan sejarah lokal yaitu kerajaan Blambangan pada masa-masa Majapahit.Latar belakang ini akan berpengaruh pada pertanian dan kebiasaan yang ada di masyarakat Banyuwangi khususnya suku using. Kebiasan suku using dalam pasca penen pari selalu tidak lepas dari kebiasaan warga dalam gagaspari (butiran-butiran padi yang terbuang atau masih melekat pada batang padi yang sudah mengalami proses penggilingan) sehingga kebiasaan ini menjadi menarik di teliti karena mempunya iperbedaan antara gagas pari suku using dan ngasak di sukujawa.
\end{abstract}

Kata kunci :budaya, gagaspari, oseng

\section{ABSTRACT}

Banyuwangi regency is a city on the eastern tip of Java island with an area of $5,782.50 \mathrm{~km}^{2}$. Banyuwangi is divided into 24 districts and 217 villages / kelurahan. Geographical conditions include the Bali strait which is the boundary with the province of Bali on the east side, the lowlands as agricultural land and fields in the northern and southern regions, as well as upland areas (Ijen and Raung volcanoes) on the western side as plantation land. In addition, Banyuwangi is the center of the kingdom based on the local history of the Blambangankingdom during the Majapahit period. This background will affect the agriculture and habits that exist in the community Banyuwangi especially using tribes.

The habit of using tribes in post-sting rays is always not free from the habit of citizens in the stingray (grains of rice that is wasted or still attached to rice stalks that have undergone the grinding process) so that this habit becomes interesting in the meticulous because it has the difference between the idea of stinging parisuku and ngasak in Javanese tribe.

Keywords: culture, stingray rod, oseng

1. Pendahuluan Kabupaten Banyuwangi merupakan kota di ujung timur pulau Jawa dengan luas wilayah
$5.782,50 \mathrm{~km}^{2}$. Banyuwangi terbagi menjadi 24 kecamatan dan 217 
desa/kelurahan ${ }^{1}$.Kondisi geografis meliputi selat Bali yang merupakan batas dengan propinsi Bali di sisi timur, dataran rendah sebagai lahan pertanian dan ladang di wilayah bagian utara dan selatan, serta daerah dataran tinggi (gunung Ijen dan gunung Raung) di sisi barat sebagai lahan perkebunan. Selain itu, Banyuwangi merupakan pusat kerajaan berdasarkan sejarah lokal yaitu kerajaan Blambangan pada masa-masa Majapahit.Latar belakang ini akan berpengaruh pada pertanian dan kebiasaan yang ada di masyarakat Banyuwangi khususnya suku using.

Menurut Koentjaraningrat ${ }^{2}$ kebudayaan dengan kata dasar budaya berasal dari bahasa sansakerta "buddhayah", yaitu bentuk jamak dari buddhi yang berarti "budi" atau "akal". Jadi Koentjaraningrat mendefinisikan budaya sebagai "daya budi" yang berupa cipta, karsa dan rasa, sedangkan kebudayaan adalah hasil dari cipta, karsa, dan rasa itu. Menurut Liliweri ${ }^{3}$ kebudayaan

${ }^{1}$ Badan Pusat Statistik kabupaten Banyuwangi, 2013.

${ }^{2}$ Koentjaraningrat.Pengantar Ilmu Antrapologi, (Jakarta: Radar Jaya Offset, 2000), halaman 181.

${ }^{3}$ Liliweri."Budaya Dalam Komunikasi Antara Budaya” Makalah Yogyakarta. PT. Lkis Pelangi Angkasa, 2002, halaman 8 . merupakan pandangan hidup dari sekelompok orang dalam bentuk perilaku, kepercayaan, nilai, dan simbol-simbol yang mereka terima tanpa sadar yang semuanya diwariskan melalui proses komunikasi dari satu generasi ke generasi berikutnya.

Lebih lanjut, Taylor dalam Liliweri mendefinisikan kebudayaan tersusun oleh kategori-kategori kesamaan gejala umum yang disebut adat istiadat yang mencakup teknologi, pengetahuan, kepercayaan, kesenian, moral, hukum, estetika, rekreasional dan kemampuan-kemampuan serta kebiasaan-kebiasaan yang didapatkan manusia sebagai anggota masyarakat. Dengan kata lain, kebudayaan mencakup semua yang didapatkan atau dipelajari oleh manusia sebagai anggota masyarakat.

Ralph Linton dalam Ihromi $^{4}$ menjelaskan bagaimana definisi kebudayaan dalam kehidupan sehari-hari berbeda dari definisi seorang ahli antropologi. Kebudayaan itu sendiri adalah seluruh cara kehidupan dari masyarakat yang manapun tidak hanya

\footnotetext{
${ }^{4}$ KomariyahDan Gunawan. "Tradisi Ayam Anggrem (Studi Tentang Relasi Gender DalamKehidupan Perkawinan Masyarakat Desa Tugu KabupatenIndramayu)".Solidarity.Vol ume 5, No. 1 (2016), halaman 2.
} 
mengenai sebagian dari cara hidup yaitu bagian yang oleh masyarakat dianggap lebih diinginkan.Bayu, Purwadi \& Marhaedi ${ }^{5}$ pewarisan kebudayaan merupakan pola dari pengertian-pengertian atau maknamakna yang terjalin secara menyeluruh dalam simbol-simbol dan ditransmisikansecara historis.

Suku Using adalah suku asli dari Banyuwangi.Using secara terminologis berasal dari kata sing-sering juga diucapkan oleh suku Usinghing yang berarti "tidak", kemudian dimaknai sebagai orangorang yang "tidak" ikut mengungsi ketika terjadi Perang Puputan Bayu, sehingga tetap menempati wilayah Blambangan yang sekarang menjadi kota Banyuwangi. .'.Menurut Praditya dan Pandya $^{7}$ Suku Using adalah salah satu suku yang ada di Banyuwangi.Suku Using adalah salah satu suku yang terancam punah jika tidak dijaga dan dilestarikan.Salah satu

${ }^{5}$ Bayu, A., Purwadi, A., \& Marhaedi, S. Jagat Osing. Banyuwangi: Rumah Budaya Osing, 2015.

${ }^{6}$ Zain Arifin \& Najwa Ilham "Suku Osing (Banyuwangi)" Makalah. Institut Seni IndonesiaSurakarta2015 halaman 2

${ }^{7}$ Praditya,Pandya.Fasilitas Kebudayaan Suku Osing Di Banyuwangi. Edimensi arsitektur. Volume 2 No.2 (Juli 2014) halaman 1. upaya untuk menjaganya adalah dengan tersedianya sebuah fasilitas (gasebu) kebudayaan yang memadai kegiatan kebudayaan Suku Using. Fasilitas Kebudayaan Suku Using ini dirancang di tengah kota Banyuwangi dengan tujuan mengenalkan, mengembangkan, dan melestarikan kebudayaan Suku Using. pengunjung dapat menikmati berbagai hiburan yang interaktif dan edukatif.

Desa Kemiri adalah sebuah desa di Kabupaten Banyuwangi yang terletak di wilayah Banyuwangi tengah, tepatnya di wilayah Kecamatan Singojuruh dan diapit oleh kecamatan lain: Kecamatan Sempu, dan Kecamatan Songgon. Desa Kemiri terletak kurang lebih $5 \mathrm{~km}$ dari pusat Kecamatan Singojuruh, dan terletak kurang lebih 30 km dari pusat pemerintahan Kabupaten Banyuwangi ke arah barat. Secara administratif desa Kemiri masuk wilayah Kecamatan Singojuruh dengan batas-batas; Utara: desa Bedewang (Kecamatan Songgon) \& desa Cantuk, Timur: desa Cantuk \& desa Gumirih (Kecamatan Singojuruh), selatan: desa Gendoh (Kecamatan Sempu), Barat: desa Sumber Baru (Kecamatan Singojuruh). Desa Kemiri 
Kecamatan Singojuruh mempunyai wilayah $4.686 .473 \mathrm{~m}^{2}{ }^{8}$.

Jadi desa Kemiri merupakan desa yang mayoritasnya masyarakatnya adalah suku Using yang beranerekaragam kebiasaan, adat istiadat dan tingkah laku yang menarik untuk di telitisehingga peneliti memutuskan untuk meneliti salah satu kebiasaan masyarakat Using setiap paska panen padi yaitu gagas pari yang di lakukan oleh kalangan ibu-ibu rumahtangga.

Lahan sawah memiliki fungsi strategis, karena merupakan penyedia bahan pangan utama bagi penduduk Indonesia. Data luas baku lahan sawah untuk seluruh Indonesia menunjukan bahwa sekitar $41 \%$ terdapat di Jawa, dan sekitar 59\% terdapat di luar Jawa. Data menunjukkan bahwa dengan bertambahnya jumlah penduduk dan meningkatnya kebutuhan akan lahan untuk berbagai sektor, konversi lahan sawah cenderung mengalami peningkatan, di lain pihak pencetakan lahan sawah baru (ekstensifikasi) mengalami perlambatan ${ }^{9}$.

${ }^{8}$ Hasil Pengukuran SISMIOP Tahun 2005 Desa Kemiri Kecamatan Singojuruh Kabupaten Banyuwangi.

${ }^{9}$ Sudaryanto T. Konversi lahan dan produksi pangan nasional". Prosiding Seminar Nasional Multifungsi dan Konversi lahan pertanian di Bogor 2 Oktober
Lahan sawah yang produktif seperti tanahtanah sawah di Jawa secara alami lebih subur bila dibanding dengan tanah-tanah sawah daerah lain yang berbahan non produktif. Adanya kesuburan tanah alami yang relatif lebih baik dan ditunjang oleh adopsi teknologi budidaya yang lebih maju, mengakibatkan terjadinya kesenjangan produktivitas yang tinggi antara lahan sawah di Jawa dan di luar Jawa ${ }^{10}$. Sehingga dapat di simpulkan bahwa keadaan tanah khususnya area persawahan sangat menjajikan untuk di jadikan lahan pertaniaan, di pulau Jawa menpunyai tingkat kesuburan yang tinggi di bandingkan dengan Daerah-daerah di luar Jawa sehingga manyarakat di sawa bantak yang berkerja sebagai petani khususnya petani padi

Orang Jawa beranggapan bahwa padi telah dirasuk oleh roh dari Dewi Sri, yang merupakan dewi kebahagiaan. Oleh karena itu, Orang Jawa memiliki kebiasaan menghormati Dewi Sri pada semua tahapan proses penanaman padi hingga pengolahan

2003. dan Jakarta 25 Oktober 2002. Puslitbang Tanah dan Agroklimat.Bogor . halaman 57-65

${ }^{10}$ Wahyunto.'Lahan Sawah Di Indonesia Sebagai Pendukung Ketahanan Pangan Nasional".Informatika Pertanian. Volume 18 No. 2, (2009) halaman 136 
hasilnya ${ }^{11}$.Padi sebagai komoditas pangan utama mempunyai nilai strategis yang sangat tinggi, sehingga diperlukan adanya penanganan yang serius dalam upaya peningkatan produktivitasnya. ${ }^{12}$

Pengertian pasca panen hasil pertanian adalah tahapan kegiatan yang dimulai sejak pemungutan (pemanenan) hasil pertanian yang meliputi hasil tanaman pangan, holtikultura, perkebunan, peternakan, dan perikanan sampai siap untuk dipasarkan ${ }^{13}$. Hasil utama pertanian adalah hasil pertanian yang merupakan produk utama yang bertujuan agar usaha pertanian bisa

${ }^{11}$ Yuliani. "Makna Tradisi "Selamatan Petik Pari" Sebagai WujudNilai-Nilai Religius Masyarakat Desa PetungsewuKecamatan Wagir Kabupaten Malang". Skripsi. UniversitasNegeri Malang, 2010halaman 26

${ }^{12}$ Fremar Refel Welang,Joachim N.K. Dumais,Martha M. Sendow. "Analisis Pendapatan Usahatani Padi SawahBerdasarkan Musim Panen Di Kelurahan Taratara SatuKecamatan Tomohon Barat Kota Tomohon"AgriSosioekonomi Unsrat. Volume 12 Nomor 2a, Juli 2016 : 107 - 124

${ }^{13}$ Surat Keputusan Presiden Republik Indonesia Nomor 47 Tahun 1986. Tentang Peningkatan Penanganan Pascapanen Hasil Pertanian. Jakarta. 17 September 1986 diperoleh melalui proses pengolahan maupun tidak melalui proses pengolahan ${ }^{14}$. Gagas pari yang dilakukan di desa Kemiri di lasanakan pada pagi hari atau siang hari tergantung mesin giling padi sudah datang akan tetapi tahapan gagas pari di mulai saat pemotongn gagang padi. Jadi di kalangan pengagas bisa mengambil padi sisa mulai dari tahap pemotongan. Proses panen/paska penen padi di Banyuwangai selalu diiringi dengan kegiatan gagas pari yang dilakukan oleh para ibu-ibu yang mengikuti proses panen. Ada salah satu kebiasaan Suku Using setiap panen padi yaitu adalah gagas pari yang dilakukan oleh ibu-ibu atau bapakbapak, akan tetapi lebih di dominasi oleh kalangan ibu-ibu. Disana para ibu-ibu tersebut menganbil sisa-sisa pari yang ada di sawah yang sudah mengalami panen pari.

Peneliti mengambil judul ini karenabelum ada penelitian tentang budaya paska panen padi suku Using di desa Kemiri. Penelitian ini diberi judul "Budaya Gagas Pari Suku Using di Desa Kemiri, Kecamatan Singojuruh, Kabupaten Banyuwangi” diharapkan penelitian ini bisa menambah

\footnotetext{
${ }^{14}$ Surat Keputusan Presiden Republik Indonesia Nomor 47 Tahun 1986. Tentang Peningkatan Penanganan Pascapanen Hasil Pertanian. Jakarta. 17 September 1986
} 
wawasan tentang kegiatan paska panen khususnya di Kabupaten Banyuwangi.

2. Kajian Literatur dan Pengembangan Hipotesis

\section{A. Pengertian}

\section{Penanganan}

\section{Pertumbuhan Padi}

Menurut Makarim dan Las ${ }^{15}$, cara yang efektif dan efisien untuk meningkatkan produksi padi nasional secara berkelanjutan adalah meningkatkan produktivitas melalui ketepatan pemilihan komponen teknologi dengan memperhatikan kondisi lingkungan biotik, lingkungan abiotik serta pengelolaan lahan yang optimal. Penggunaan teknologi sistem tanam dalam budidaya padi diharapkan dapat mempengaruhi hasil produksi, dan pada akhirnya akan mempengaruhi pendapatan petanian. Yoshie dan Rita ${ }^{16}$ mengatakan, teknologi budidaya

${ }^{15}$ Makarim, A.K. dan I. Las.Terobosan Peningkatan Produktivitas Padi Sawah Irigasi melalui Pengembangan Model Pengelolaan Tanaman dan Sumberdaya Terpadu (PTT). Badan Litbang Pertanian 2005. Halaman 115-127.

${ }^{16}$ Sri Hariningsih Pratiwi. "Pertumbuhan Dan Hasil Padi (OryzaSativa L.) Sawah Pada Berbagai MetodeTanam Dengan PemberianPupuk Organik" Gontor AGROTECH Science.Volume. 2 No. 2, Juni 2016 yang tepat tidak hanya menyangkut masalah penggunaan varietas unggul, tetapi juga pemilihan metode tanam yang tepat.Pada umumnya petani padi sawah di Indonesia menggunakan metode tanam pindah (konvensional) pada kegiatan usahataninya.

Pada metode tanam pindah, bibit padi ditanam dengan jarak tanam rapat dengan jarak tidak lebih dari $20 \mathrm{~cm}$ x $20 \mathrm{~cm}$. Teknologi budidaya lain yang dapat diterapkan sebagai upaya peningkatan produksi padi adalah dengan metode tanam jajar legowo yaitu dengan prinsip pemberian kondisi pada setiap barisan tanam padi untuk mengalami pengaruh sebagai tanaman pinggir. Teknologi berikutnya adalah metode tanam SRI (Sistem of Rice Intensification) yaitubudidaya tanaman padi intensif dan efisien dengan proses manajemen sistem perakaran yang berbasis pada pengelolaan yang seimbang terhadap tanah, tanaman dan air ${ }^{17}$.Disamping itu bahan organik berfungsi sebagai amelioran yang dapat memperbaiki jumlah dan aktivitas mikroba dan sumber hara dalam

17 Juhendi, E..Pengembangan Pertanian Hemat Air melalui SRI (System of Rice Intensification) dan PET (Pembelajaran Ekologi Tanah). Departemen Pekerjaan Umum, Cirebon (2008). 
tanah sehingga dapat meningkatkan kualitas $\operatorname{tanah}^{18}$.

\section{B. Luas Lahan Sawah di Desa Kemiri}

Desa kemiri adalah wilayah kecamatan Singojuruh dengan luas wilayah yaitu: $4,686,473$ yang terdiri dari sawah seluas $3,808,275 \mathrm{~m}^{2}$ dengan persentase $81.2610 \%$, tanah darat seluas 284,523 $\mathrm{m}^{2}$ dengan persentase $6.0712 \%$, TKD seluas 191,571 $\mathrm{m}^{2}$ dengan persentase $4.0877 \%$, BD seluas $240 \mathrm{~m}^{2}$ dengan persentase $0.0051 \%$, TN seluas 2,761 $\mathrm{m}^{2}$ dengan persentase $0.0589 \%$, perkantoran $6,929 \mathrm{~m}^{2}$ dengan persentase $0.1479 \%$, perumahan seluas $347,268 \mathrm{~m}^{2}$ dengan persentase $7.4100 \%$, sekolah seluas $11,314 \mathrm{~m}^{2}$ dengan persentase $0.2414 \%$, masjid \& mushola seluas 5,259 $\mathrm{m}^{2}$ dengan persentase $0.1122 \%$, ponpes seluas $2,415 \mathrm{~m}^{2}$ dengan persentase $1.2606 \%$, lapangan seluas $7,688 \mathrm{~m}^{2}$ dengan persentase $4.0131 \%$, pemakaman seluas $18,230 \mathrm{~m}^{2}$ dengan persentase $9.5161 \%$ jadi jumlah luas desa kemeri keseluruhan adalah 4,686,473 dengan persentase

\footnotetext{
${ }^{18}$ Setyorini, et al. 2006.Pupuk Organik dan Pupuk Hayati. Dalam http://balittanah.litbang.deptan.go.id/d okumentasi/buku/pupuk/pupuk2.pdf
}

Topografi Desa Kemiri berupa dataran sedang yang mana wilayahnya bagian selatan dikelilingi oleh sungai kumbo, sebagian sungai Kemapak dan bukit Klasi, sedang wilayah utara dikelilingi oleh sungai Badeng, Suhu udara Desa Kemiri berkisar 21-27 ${ }^{\circ} \mathrm{C}$, dengan ketinggian rata-rata dari permuka-an air laut $\pm 65 \mathrm{~m} \mathrm{dpl}$, sedangkan curah hujan rata-rata tiap tahun berkisar 1000 - $2000 \mathrm{~mm}$, dengan demikian kondisi alam Desa Kemiri cukup sejuk dengan cukup banyak hembusan angin laut dan gunung. ${ }^{19}$

\section{Pengertian Paska Penen Padi}

Menurut jurnal "Makna tradisi "selamatan petik pari” sebagai wujudnilainilai religius masyarakat desa petungsewukecamatan wagir kabupaten malang" yang di tulis Eka Yuliyanimenyebutkan bahwa1. Asal mula tradisi "Selamatan petik pari" telah ada sejak zaman nenek moyang orang Jawa, Masyarakat Desa Petungsewu yang mayoritas bekerja sebagai petani telah lama menjalankan tradisi ini,salah satu sesajian yang dianggap penting bagi masyarakat

\footnotetext{
${ }^{19}$ Hasil Pengukuran SISMIOP Tahun 2005 Desa Kemiri Kecamatan Singojuruh Kabupaten Banyuwangi
} 
petungsewu adalah sesajian dalam membuka lahan pertanian sampai masa panen tiba. Masyarakat desa ini mempercayai adanya Dewi Sri yang menjaga tanaman agar tidak terkena hama padi dan hasil panen berlimpah. Pengaruh kebudayaan hindu di Desa Petungsewu ini menambah pembendaharaan simbolisme dan pemujaan kepada Dewa-Dewi hindu,hasil asimilasi inilah yang melahirkan Dewi Sri, tokoh simbolik masyarakat petani Jawa,dan tradisi Selamatan Petik Pari ini ditujukan khusus kepada Dewi Sri agar melindungi tanaman padinya terhadap gangguan-gangguan hama tanaman padi dan mendapatkan hasil panen yang berlimpah, selain itu tujuan diadakan tradisi selamatan petikpari ini ditujukan untuk mereka yang berjasa membantu dalam pengerjaan sawahnya $^{20}$.Sedangkan $^{2}$ menurutFremar Refel Welang,Joachim N.K. Dumais,Martha M.Sendow dalam judulnya "Analisis pendapatan usahatani padi sawahberdasarkan musim panen di kelurahan taratara satukecamatan tomohon

${ }^{20}$ Eka Yuliyanti, Makna Tradisi "Selamatan Petik Pari" Sebagai WujudNilai-Nilai Religius Masyarakat Desa PetungsewuKecamatan Wagir Kabupaten Malang, Skripsi. 2010 halaman 91 barat kota tomohon'.yang menyimpulkan bahwa:

1. Berdasarkan hasil Penelitian pendapatan usahatani padi sawah yang dikelolah oleh petani responden di Kelurahan Taratara Satu berdasarkan musim panen, untuk musim panen 1 (satu) dan musim panen 2 (dua) berbeda. Hal tersebut dipengaruhi oleh iklim, harga jual dan biaya.

2. Nilai $\mathrm{R} / \mathrm{C}$ rasio lebih dari satu, artinya usahatani padi sawah di Kelurahan Taratara Satu mampu memberikan keuntungan dan usahatani tersebut layak untuk diusahakan ${ }^{21}$.

Jadi kesimpulan dari kedua jurnal tersebut adalah menjelaskan budaya atau tradisi dan pendapatan paska panen padi yang dilakukan di daerah-daerah Indonesia ini masih sedikit tentang penelitian paska panen padi ini, sehingga bisa di tarik kesimpulan bahwa penelitian yang peneliti ambil dengan judul "budaya gagas pari suku

\footnotetext{
${ }^{21}$ Fremar Refel Welang. Analisis Pendapatan Usahatani Padi Sawah.AgriSosioekonomi Unsrat. Volume 12 Nomor 2A, Juli 2016 halaman 107 124
} 
Using di Banyuwangi ini masih belum ada yang meneliti jadi baru.

Penulisan skrisi ini menggulakan pendekatan teori kebudayaan karenaEvolusionisme adalah perspektif antropologis yang menekankan anilisis pada kompleksitas kebudayaan berkembang sepanjang waktu. Evolusionisme merupakan gagasan untuk analisis teoritis dalam antropologi yang menggunakan dasar bahwa kebudayaan dari setiap masyarakat akan maju berkembang melalui tahapan evolusi yang sama. E. B Taylor dan L. H. Morgan mencetuskan perkembangan kebudayaan manusia pada beberapa tahap. Tahap pertama adalah liar (savegery) yang hidup dengan mengumpulkan buah-buahan, tanaman liar, dan lain sebagainya. Kedua adalahbarbarisme (barbarism) mengenal pembuatan alat-alat seperti dari tanah liat atau tembikar, mengadakan irigasi, serta mulai mengembangkan alat-alat logam.Tahap yang ketiga adalah kebudayaan yang beradab (civilization) yang mulai mengembangkan dan memakai alfabet.

\section{Pengertian gagas pari}

Gagas pari adalah kegiatan mengambil sisa-sisa padi yang terbuang saat proses pemotongan padi dan penggilingan padi (pemisahan biji padi dari gagang padi) sehingga momentum-momentum tersebut di gunakan oleh kalangan ibu-ibu rumah tangga dan sebagian kecil juga ada bapak untuk mencari biji-biji padi yang terbuang sehingga biji-biji padi tersebut bisa membantu kebutuhan ekonomi keluarga. Adapun perbedaan antara penggagas wanita dengan penggagas laki-laki adalah sebagai berikut:

\section{E. Penggagas wanita}

Penggagas wanita yang mayoritas adalah ibu-ibu rumah tanga kebanyakan memulai budaya gagas pari dari awal yaitu dari proses pemotongan padi sampai penggilingan padi. Kebanyakan dari kalangan ibu-ibu mengikuti waktu penggilingan padi yang menunggu di samping mesin pembuangan sampai-sampai mereka nekat duduk di kumpulan dami demi mencari sisa-sisa padi yang masih ada di gagang padi.

\section{F. Penggagas laki-laki}

Penggagas laki-laki umumnya melakukan gagas pari hanyalah iseng karena mereka adalah para pekerja yang di perkerjakan oleh juragan untuk mengamgkat padi aatu memnggu padi, dan umunya juga mereka mencari padi setelah terjadi pemotongan padi dan tidsak mengikuti proses penggilingan padi sehingga para penggagas laki-laki ini memperoleh padi jauh lebih sedikit dari kalangan ibu-ibu. Adapun yang melatarbelakangi hasil penggagas laki-kali jauh lebih sedikit dari kalangan ibu-ibu adalah mereka mempunyai tujuan padi yang hasil gagas tadi di berikan 
untuk memberi makan ternak mereka seperti : Ayam dan Burung Dara

\section{G. Kategori seseorang penggagas pari}

Kegiatan paska penen padi yang terjadi di desa kemiri tidaklah lengkap tanpa adanya seseorang yang memnggagas pari karena menggagas pari sangatlah kental dengan budaya panen padi,terutama di desa kemiri pengkategorian seorang pnggagas adalah: mereka membaya topi tani, berkerudung ini berguna untuk melindungi rambut mereka diri dami( sisa gagang padi yang sudah di giling), memakai kaos atau baju olah raga sisa anaknya bersekolah, membawa wadah/tempat untuk menyimpan hasil gagasan.

\section{Keunikan gagas pari di desa kemiri}

1. Mereka semua menggunakan kerudung untuk melindungi rambut mereka

2. Setiap tumpukan (tapelan) padi sudah ada pengagasnya sendirisendiri (blok-blok)

3. Kebanyakan dari mereka menggunakan seragam olahraga anak nya yang sudah tidak terpakai

4. Sebelum tumpukan padi di giling bergantian kalangan penggas pari mengisi waktu mereka dengan bergurau atau bercanda tawa

5. Umunya penggagas pari berkelompok yang terdiri dari luar lingkup terdekat

\section{Metode Penelitian}

Studi etnografis berusaha meneliti suatu kelompok budaya tertentu bedasarkan pada pengamatan dan kehadiran peneliti di lapangan dalam waktu yang lama.pada umumnya ada 2 tipe etnogarfis yaitu etnografis realis di mana peneliti berperan sebagai pengamat"objek", merekam fakta dengan sikapyang tidak memihak dan etnografis kritis di mana studinya di arahkan untuk meneliti sistem kultural dari kekuasaan, hak istimewa, dan otoritas dalam masyarakat untuk menyuwarakan aspirasi kaum marjinal dari berbagai kelas, ras, dan gender $^{22}$.

Jadi di sini peneliti menjadi etnografis realis di mana peneliti berperan sebagai pengamat objek gagas pari dalam proses paska penen padi di desa Kemiri yang terdiri dari 2 dusun yaitu: dusun Kemiri dan dusun Rukem,

${ }^{22}$ W.Creswell, J. (N.D.).Penelitian Kualitatif Dan Desain Riset.Malang: Pustaka Belajar Edisi 2. 1998 halaman 65 
dalam proses panen padi peneliti merekam adegan demi adegan proses gagas pari tanpa mempunyai sikap yang memihak maksud memihak di sini adalah tidak berfokus pada satu objek saja.

\section{Daftar Pustaka}

Badan Pusat Statistik Kabupaten Banyuwangi, 2013. Banyuwangi Dalam Angka. Banyuwangi : Badan Pusat Statistik.

Bayu, A., Purwadi, A., \& Marhaedi, S. 2015.Jagat Osing. Banyuwangi: Rumah Budaya Osing.

Fremar Refel Welang,Joachim N.K. Dumais,Martha M. Sendow.2016 : 107 - 124 "Analisis Pendapatan Usahatani Padi SawahBerdasarkan Musim Panen Di Kelurahan Taratara SatuKecamatan Tomohon Barat Kota Tomohon"AgriSosioekonomi Unsrat.Volume 12 Nomor 2a.

Hamidi.2004. Metode Penelitian Kualitatif: Aplikasi Praktis Pembuatan Proprosal Dalam Laporan Penelitian. Malang.

Juhendi, E. 2008.Pengembangan Pertanian Hemat Air Melalui SRI (System Of Rice Intensification) Dan PET (Pembelajaran Ekologi Tanah). Departemen Pekerjaan Umum, Cirebon. Koentjaraningrat. 2000. Pengantar Ilmu Antrapologi, Jakarta: Radar Jaya Offset, KomariyahDan Gunawan. 2016 ."Tradisi Ayam Anggrem (Studi Tentang Relasi Gender DalamKehidupan Perkawinan Masyarakat Desa Tugu KabupatenIndramayu)".Solidarity. Volu me 5, No. 1.
Liliweri.2002. "Budaya Dalam Komunikasi Antara Budaya” Makalah Yogyakarta.PT. Lkis Pelangi Angkasa. Praditya, Pandya.2014.Fasilitas Kebudayaan Suku Osing Di Banyuwangi. Edimensi Arsitektur. Volume 2 No.2.

Setyorini, Et Al. 2006. Pupuk Organik Dan Pupuk Hayati. Dalam Http://Balittanah.Litbang.Deptan.Go.Id/ Dokumentasi/Buku/Pupuk/Pupuk2.Pdf.

Sudaryanto T.2003. Konversi Lahan Dan Produksi Pangan Nasional".Prosiding Seminar Nasional Multifungsi Dan Konversi Lahan Pertanian Di Bogor 2 Oktober.Dan Jakarta 25 Oktober 2002.Puslitbang Tanah Dan Agroklimat. Bogor.

Sugiono, P. 2011.Metode Penelitian Kuantitatif Kualitatif Dan $R \& D$. Bandung: Alfabeta.

Sugiyono.2006. Metode Penelitian Kuantitatif, Kualitatif Dan $R$ \& $D$. Bandung:Alfabeta.

Sugiyono.2006. Metode Penelitian Kuantitatif, Kualitatif Dan $R$ \& $D$. Bandung:Alfabeta.

Sri Hariningsih Pratiwi.2016. "Pertumbuhan Dan Hasil Padi (OryzaSativa L.) Sawah Pada Berbagai MetodeTanam Dengan PemberianPupuk Organik" Gontor Agrotech Science.Volume. 2 No. 2.

Wahyunto. 2009. "Lahan Sawah Di Indonesia Sebagai Pendukung Ketahanan Pangan Nasional". Informatika Pertanian. Volume 18 No. 2.

W.Creswell, J. (N.D.).1998.Penelitian Kualitatif Dan Desain Riset.Malang: Pustaka Belajar Edisi 2.

Zain Arifin \& Najwa Ilham.2015. "Suku Osing (Banyuwangi)" Makalah. Institut Seni IndonesiaSurakarta. 